\title{
Catalytic Esterification of Medium-Chain Fatty Acids: Kinetic Investigations
}

\author{
Maria Kulawska $^{1}$, Maria Organek ${ }^{2}$, Wiesław Organek $^{1}$ \\ ${ }^{1}$ Institute of Chemical Engineering, Polish Academy of Sciences, Gliwice, Poland \\ ${ }^{2}$ Institute of Heavy Organic Synthesis Blachownia, Kędzierzyn-Koźle, Poland \\ Email: ^m.kul@iich.gliwice.pl
}

How to cite this paper: Kulawska, M., Organek, M. and Organek, W. (2017) Catalytic Esterification of Medium-Chain Fatty Acids: Kinetic Investigations. International Journal of Organic Chemistry, 7, 336-345. https://doi.org/10.4236/ijoc.2017.74028

Received: October 17, 2017

Accepted: December 11, 2017

Published: December 14, 2017

Copyright (c) 2017 by authors and Scientific Research Publishing Inc. This work is licensed under the Creative Commons Attribution International License (CC BY 4.0).

http://creativecommons.org/licenses/by/4.0/

(c) (i) Open Access

\begin{abstract}
Medium-chain fatty acids (MCFA) are straight-chain fatty acids with aliphatic tails of $6-12$ carbons, which can form medium-chain triglycerides. They are found mostly in animal fats and in the tropical vegetable oils. Because of their wide applications in industry, there is a growing demand of esters of medium-chain fatty acids production. The aim of our work was investigations of the kinetics of the synthesis of esters of MCFA in the presence of dowex catalyst in wide range of process parameters. Hexanoic, octanoic and decanoic acids were esterified with n-octyl alcohol in the presence of sulfuric acid and commercial dowex W50X8 as catalysts in an experimental semi-periodic glass tank reactor with instantaneous and complete water removal. Because of complete removal of water from the reacting mixture, thus eliminating the reverse hydrolysis reaction, the esterification can be assumed as irreversible reaction. The temperature range was $393-423 \mathrm{~K}$, the range of initial mole ratio of alcohol to acid was $3-10$. The kinetic parameters are given. The reaction kinetics appeared to be of the first order with respect to the acid. The effect of temperature on the reaction rate follows the Arrhenius equation well.
\end{abstract}

\section{Keywords}

Decanoic Acid, Esterification, Heterogenous Catalyst, Hexanoic Acid, Octanoic Acid, Octyl Alcohol, Sulfuric Acid

\section{Introduction}

Medium-chain fatty acids (MCFA) are straight-chain fatty acids with aliphatic tails of $6-12$ carbons, which can form medium-chain triglycerides. They are found in tropical vegetable oils (e.g. coconut milk, palm oil) and animal fats (e.g. butter, breast milk, tallow of goats and rabbits). These fats contribute to the 
health of the immune system and are taken up directly to the portal vein during lipid digestion for quick energy. Hexanoic (caproic, C6:0) and octanoic (caprylic, C8:0) acids are oily liquids at room temperature with a slightly unpleasant rancid-like smell and taste, decanoic (capric, C10:0) acid is a solid; with boiling temperature increasing from $478 \mathrm{~K}, 510 \mathrm{~K}$ to $543 \mathrm{~K}$, respectively. Molar masses of described acids are $116.16 \mathrm{~g} / \mathrm{mol}, 144.21 \mathrm{~g} / \mathrm{mol}$, and $172.26 \mathrm{~g} / \mathrm{mol}$, respectively. They have wide applications. Currently, caprylic specimens used in the traditional and alternative medicine as medicaments or diet supplements are usually a mixture of caprylic acid and mono- and dicaprylates, often they are a mixture of caproic, caprylic and capric acids [1] [2]. They have antimicrobial and antifungal properties and are used as food additives. Esters of hexanoic, octanoic and decanoic acids are important products in food, pharmaceutical and cosmetic industry as emollients, flavor and fragrance agents, e.g. ethyl octanoate has a scent of fruits and therefore it is an important component giving proper smell to wines. Esterification goes with a relatively slow rate, so a catalyst should be employed. Although there is comprehensive literature concerning esterification processes in general, majority of literature reports concerns reactions of carboxylic acids with short-chain alcohols, e.g. [3] [4] [5]. Literature reports on the kinetics of the esterification of octanoic acid are very scarce, and there are not any kinetic data concerning this reaction catalysed by heterogeneous catalysts. Santos et al. and L. Urteaga et al. [6] [7] investigated the esterification of octanoic acid with n-octyl alcohol in the temperature range $333-353 \mathrm{~K}$ and an excess of acid using classic catalysts of Lewis acid type, namely metal chlorides of valencies I, II, III and IV. The best efficiency has been found in the reaction over ferric chloride. Authors used vacuum system to remove water. They found second order power law kinetic model.

The aims of our work were investigations on the kinetics of the syntheses of caproic, caprylic and capric acids with n-octyl alcohol. Catalysts have been used. Since many years, sulfuric acid has been applied in chemical catalysis. It is a classic catalyst of esterification, used nowadays as well [8]. As strong acid, it gives the highest reaction rate, so it is a good starting point for wide kinetic investigations. Its disadvantage is a potential for generation of some amounts of by-products, giving a colour change or blushing of a product. Extensive demand for cleaner environment is an important incentive to improve production of esters. At present, sulfuric acid is replaced by less aggressive catalysts. Dowex 50WX8-100, of "Dow Chemical" production, is a strong acid cation exchange resin based on polystyrene crosslinked with 8 mass \% divinylbenzene. The concentration of inbuilt sulfonic groups is $1.7 \mathrm{mlq} / \mathrm{dm}^{3}$. It can be used many times after simply rinsing [5] [9] [10] [11].

\section{Materials and Methods}

Hexanoic acid, octanoic acid, decanoic acid, n-octyl alcohol, sulfuric acid, all of AR grade, purchased from Avantor Performance Materials Poland; dowex 
50WX8-100 purchased from Sigma-Aldrich. All chemicals and catalysts were used without further purification.

The main component of the apparatus was a glass flask of $1 \mathrm{dm}^{3}$ capacity placed in a thermostat. The reactor was equipped with a thermometer, sampling cock, azeotropic head with a cooler and a magnetic stirrer. In industrial settings, the reaction is taken to completion by removal of water [12]. The equipment used by us enables water to be removed instantaneously and completely from the reacting mixture; a sufficiently high flow of inert gas has been used. The level of the nitrogen flow was determined experimentally by using progressively increasing nitrogen flow rates until further increase in the flow rate has no effect. The content of water was analytically determined by electrometric titration using the method of Karl Fischer. Under these conditions the reaction can be assumed as irreversible.

The experiments were carried out in the range of initial molar ratios of alcohol to respective acid, $b=c_{A L C}^{0} / c_{a c}^{0}$, equal to 3:1, 5:1, 10:1. The effect of temperature on reaction rate was determined at $b=5: 1$, in the range of temperatures $393 \mathrm{~K}-423 \mathrm{~K}$. The concentration of the catalyst was determined experimentally constant in every experimental batch. All experiments were conducted under atmospheric pressure. At least two reactions were performed under the same experimental conditions and then the average values of the conversion were calculated. The changes of the reagents concentrations in the course of the reaction have been determined analytically and chromatographically. Analyses of the conversion degree of acids were based on the acid number determination in the samples taken from the reacting mixture. The part of the experimental data is presented in Figures 1-3. Chromatographic quantitative analysis has been conducted using PerkinElmer GC/FID chromatograph of Autosystem XL type. The reaction mixture was separated into components using a $30 \mathrm{~m}$ capillary column HP-5ms in the temperature range $373-573 \mathrm{~K}$. The temperature of detector was $583 \mathrm{~K}$. Qualitative analysis has been conducted using Agilent Technologies 7890A mass detector 5977B (GC/MS) with catalogue of mass spectrum MS SEARCH 2.2. Mass spectra were performed in the range of $\mathrm{m} / \mathrm{z}$ equal to $40-400$ $\mathrm{Da}$ at the transfer line temperature of $573 \mathrm{~K}$, at the ions source temperature of $603 \mathrm{~K}$, at the quadrupole temperature of $423 \mathrm{~K}$. Ionization energy of electron beam was $70 \mathrm{eV}$. Before the analysis, $N, O$-bis(trimethylsilyl)acetamide (BSA) has been added to the sample and heated to convert organic acids and alcohols (which have active hydrogen atoms) into more volatile trimethylsilyl derivatives.

Chromatographic analyses of random samples of the reacting liquid revealed only small amounts of by-products. They are n-octyl esters of aliphatic acids C8 - C12 and dioctyl ether, see Table 1 and Table 2. Their amounts increased with temperature. Under continuous water removing in the presence of a strong acid as catalyst and an excess of alcohol, dialkyl ethers can be formed as a result of dehydration reaction of alcohol. This occurs especially over sulfonic acid ion-exchange resins [13]. 


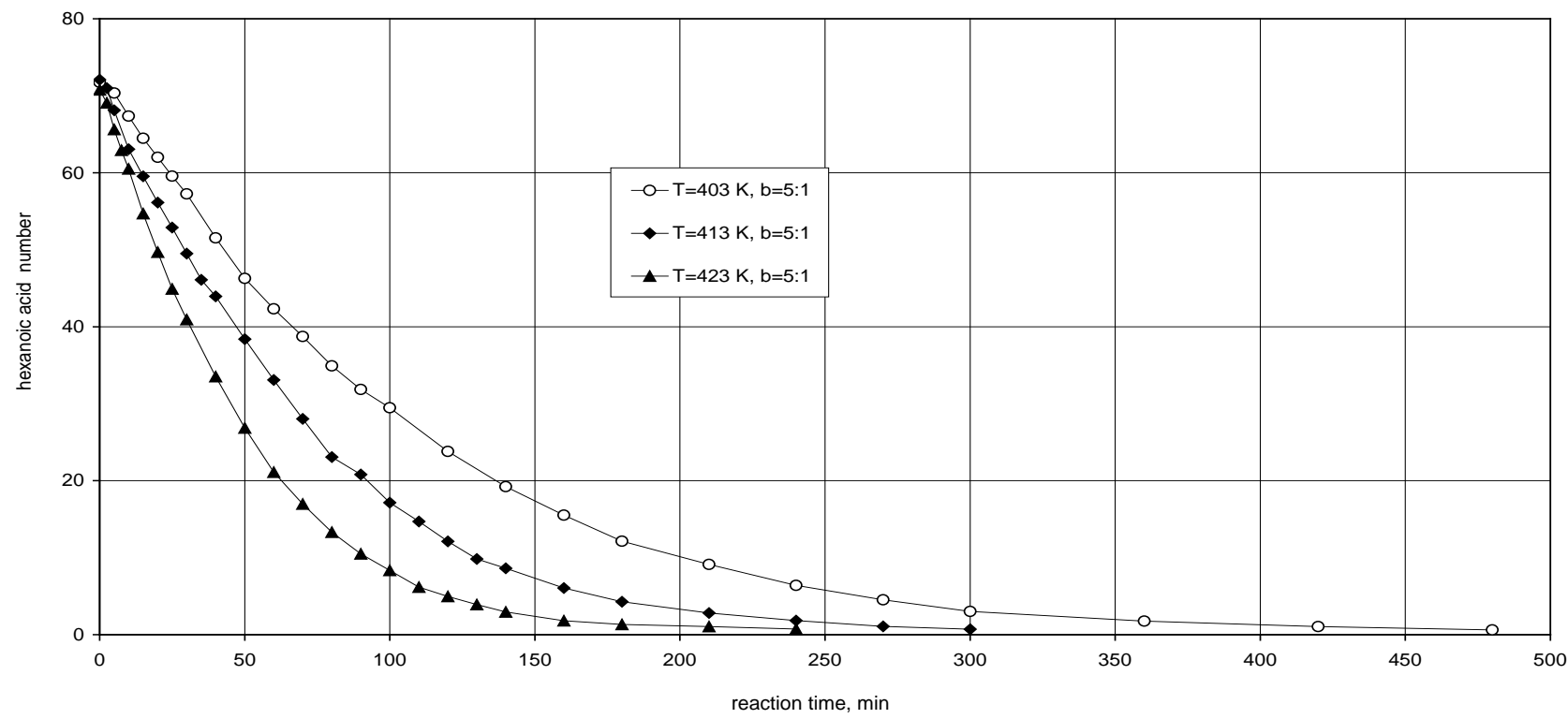

Figure 1. Course of acid number during esterification of hexanoic acid with n-octanol over 0.70 mass $\%$ of dowex 50 WX8 catalyst for various temperatures at $b=5: 1$.

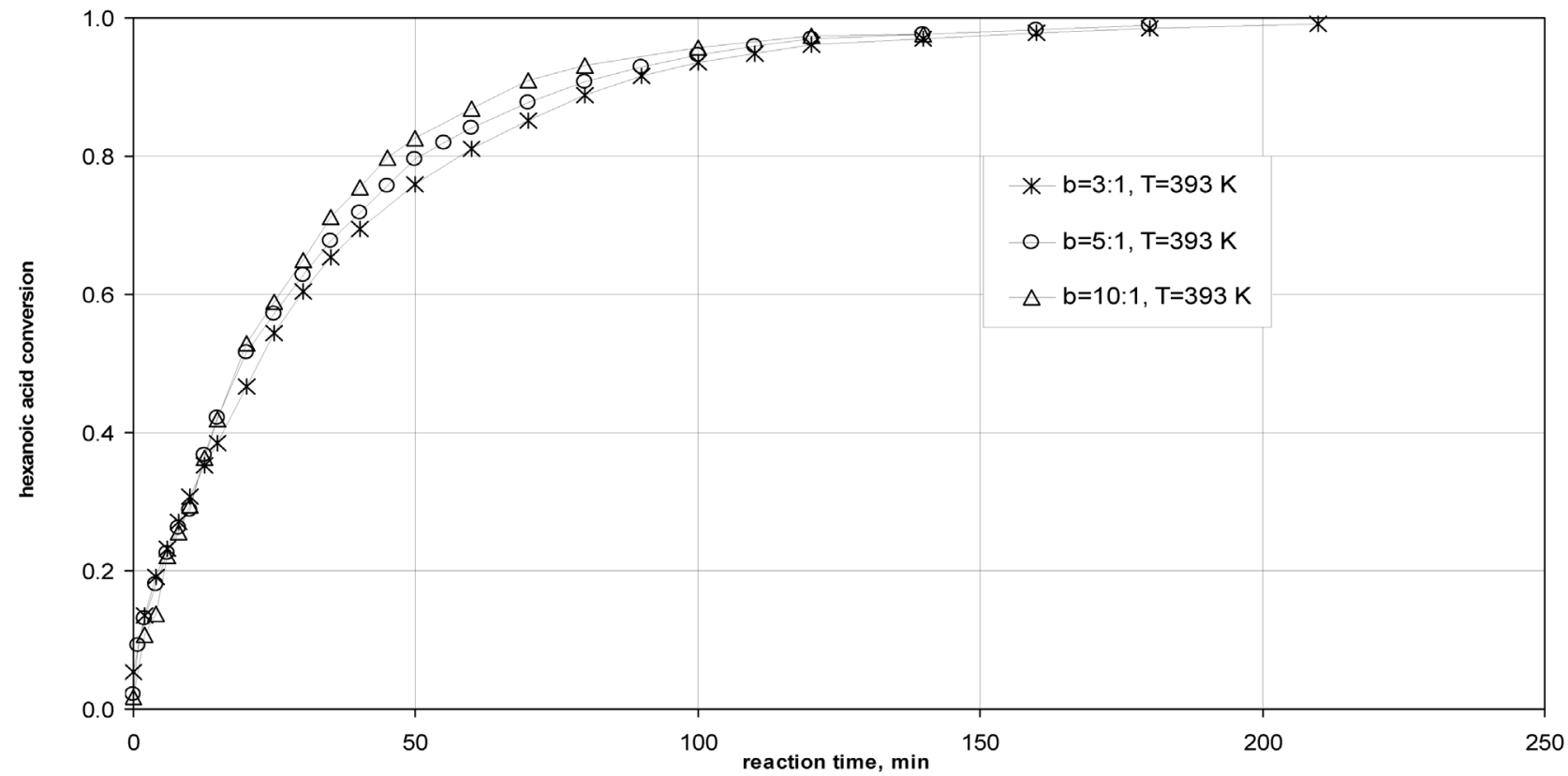

Figure 2. Course of hexanoic acid conversion during esterification with n-octanol over 0.025 mass $\%$ of sulfuric acid catalyst for various initial mole ratios of substrates at $\mathrm{T}=393 \mathrm{~K}$.

Table 1. Synthesis of 1-octyl octanoate over 1 mass \% of dowex 50WX8 catalyst. Chromatographic analysis of end product mixture, $\mathrm{b}=3: 1$.

\begin{tabular}{cccc}
\hline \multirow{2}{*}{ Temperature } & \multicolumn{3}{c}{ Composition, mass $\%$} \\
\cline { 2 - 4 } & $\mathrm{T}=393 \mathrm{~K}$ & $\mathrm{~T}=413 \mathrm{~K}$ & $\mathrm{~T}=433 \mathrm{~K}$ \\
\hline 1-octanol & $48.6 \%$ & $46.6 \%$ & $42.8 \%$ \\
Octanoic acid & $0.2 \%$ & $0.2 \%$ & $0.7 \%$ \\
1-octyl octanoate & $49.7 \%$ & $48.7 \%$ & $49.4 \%$ \\
Others & $1.5 \%$ & $4.5 \%$ & $7.1 \%$ \\
\hline
\end{tabular}




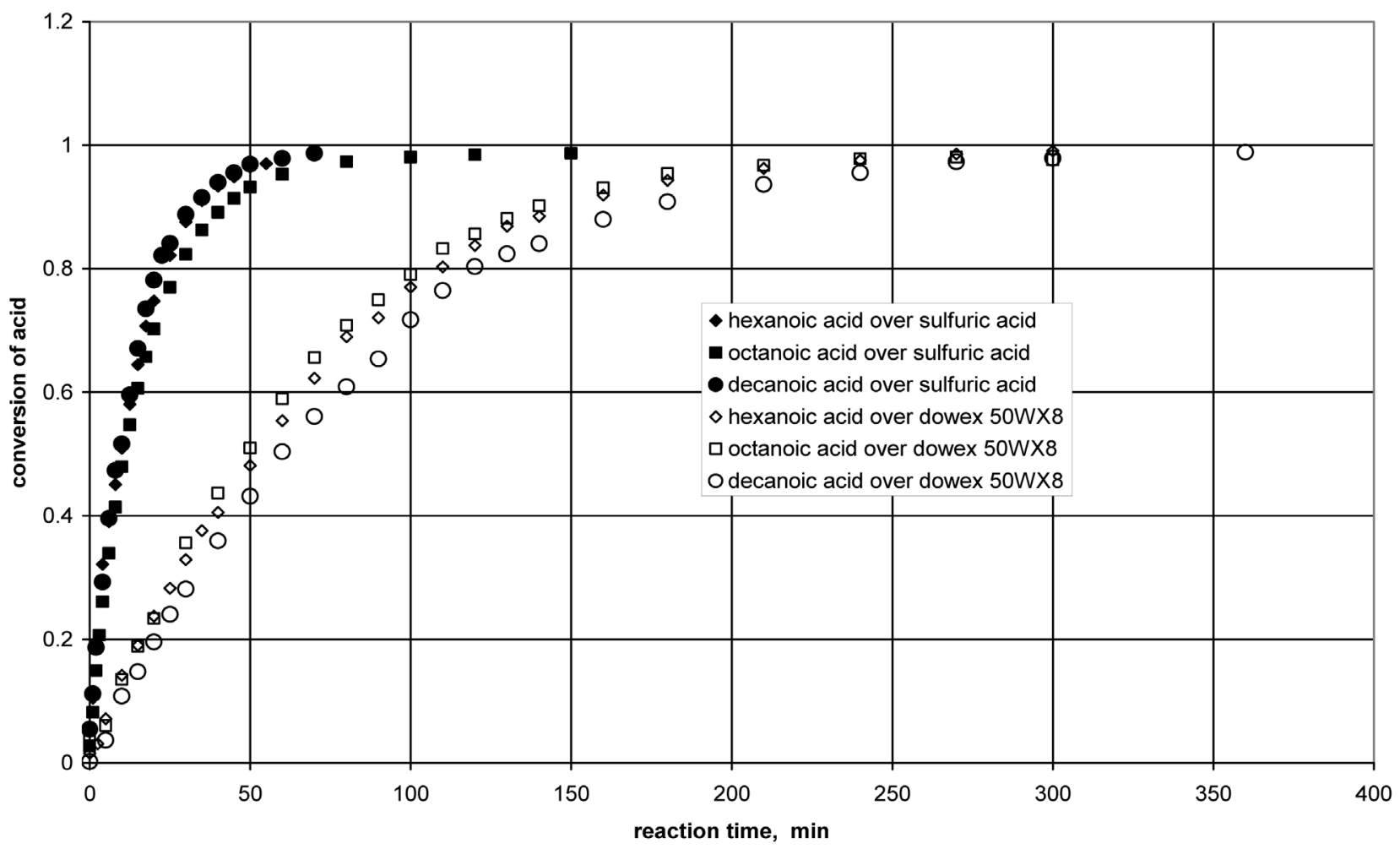

Figure 3. Comparison of acid conversion during esterification with n-octanol over sulfuric acid catalyst and over dowex $50 \mathrm{WX} 8$ catalyst at $\mathrm{T}=413, \mathrm{~b}=5: 1$.

Table 2. Synthesis of 1-octyl decanoate over 1 mass $\%$ of dowex 50WX8 catalyst. Chromatographic analysis of end product mixture, $b=5: 1$.

\begin{tabular}{ccc}
\hline Temperature & \multicolumn{2}{c}{ Composition mass $\%$} \\
\cline { 2 - 3 } & $\mathrm{T}=403 \mathrm{~K}$ & $\mathrm{~T}=423 \mathrm{~K}$ \\
\hline 1-octanol & $66.3 \%$ & $56.7 \%$ \\
Decanoic acid & $0.1 \%$ & $0.1 \%$ \\
1-octyl decanoate & $30.4 \%$ & $32.1 \%$ \\
Dioctyl ether & $2.4 \%$ & $10.2 \%$ \\
Others & $0.8 \%$ & $0.9 \%$ \\
\hline
\end{tabular}

\section{Results and Discussion}

The results of our investigations are presented in Table 3. The hydrolysis of esters has been avoided and the high conversions of all acids have been obtained. Mass transfer resistance was avoided because of good mixing of the reaction mixture. There were no diffusion effects in and out catalyst grain because of significant differences between size of product molecule and sieve openings of dowex catalyst, at least five orders of magnitude. Under these conditions both systems could be considered as homogeneous and irreversible. Practically, there is no effect of excess of alcohol on the conversion of respective acid. The reaction could be described by the first order power law kinetic equation with respect to acid only; no second-order kinetics have been observed. 
Rate constant of pseudo-first order reaction, $k$, has been estimated after arrangement and integration of the classic batch reactor mass-balance equation with concentrations expressed by conversion. Goodness of fit for the esterification is shown in Figure 4 and Figure 5. The effect of temperature on the reaction rate follows the Arrhenius equation well, see Figures 6-8. Only small effect of carbon chain length of acid on reaction rate has been observed.

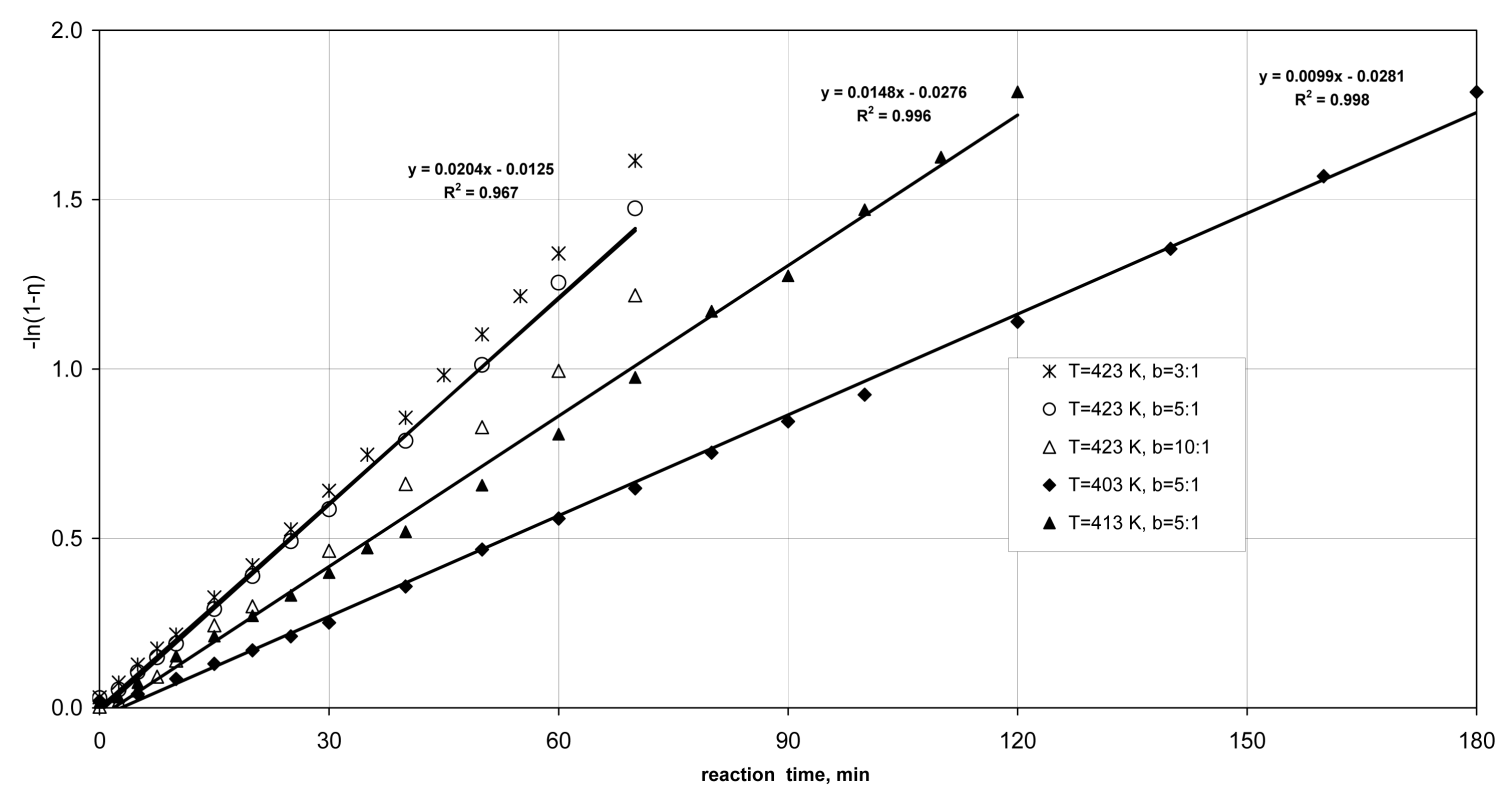

Figure 4. Quality of fit to experimental data for esterification of hexanoic acid with n-octanol over 0.025 mass $\%$ of dowex 50 WX8 catalyst.

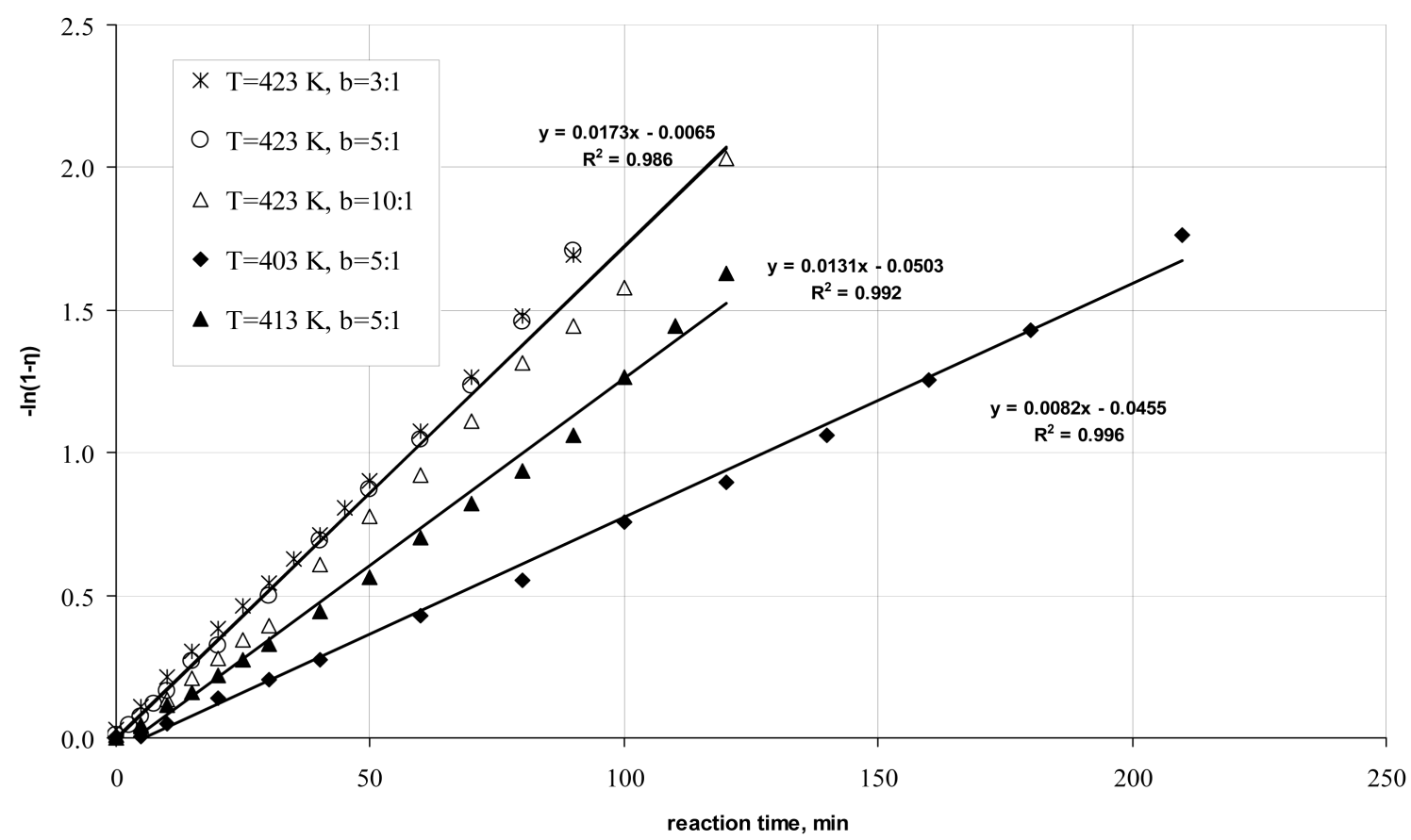

Figure 5. Quality of fit to experimental data for esterification of decanoic acid with n-octanol over 0.70 mass $\%$ of dowex $50 \mathrm{WX} 8$ catalyst. 


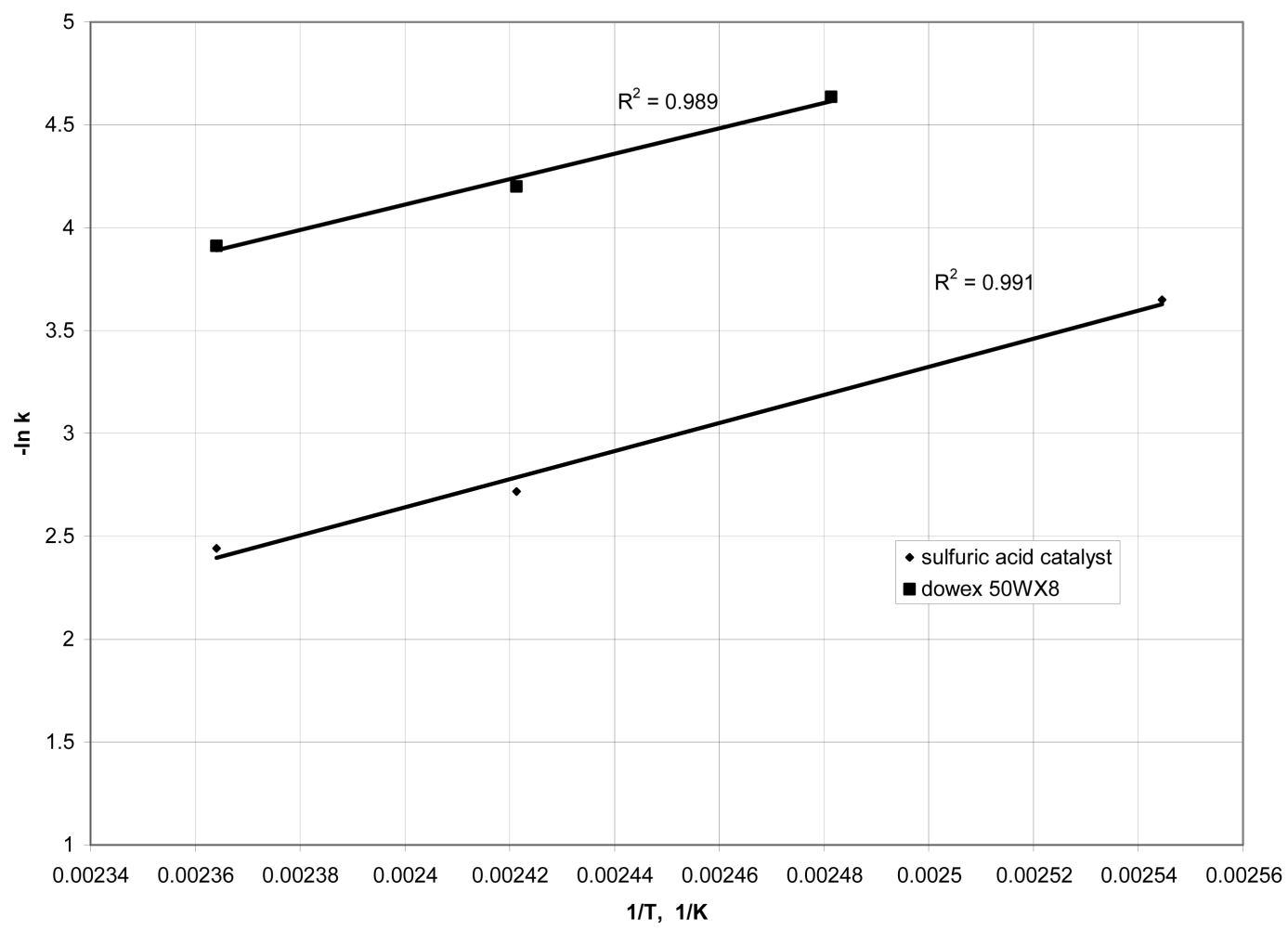

Figure 6. Arrhenius plot for esterification of hexanoic acid with n-octanol over sulfuric acid catalyst and over dowex 50WX8 catalyst.

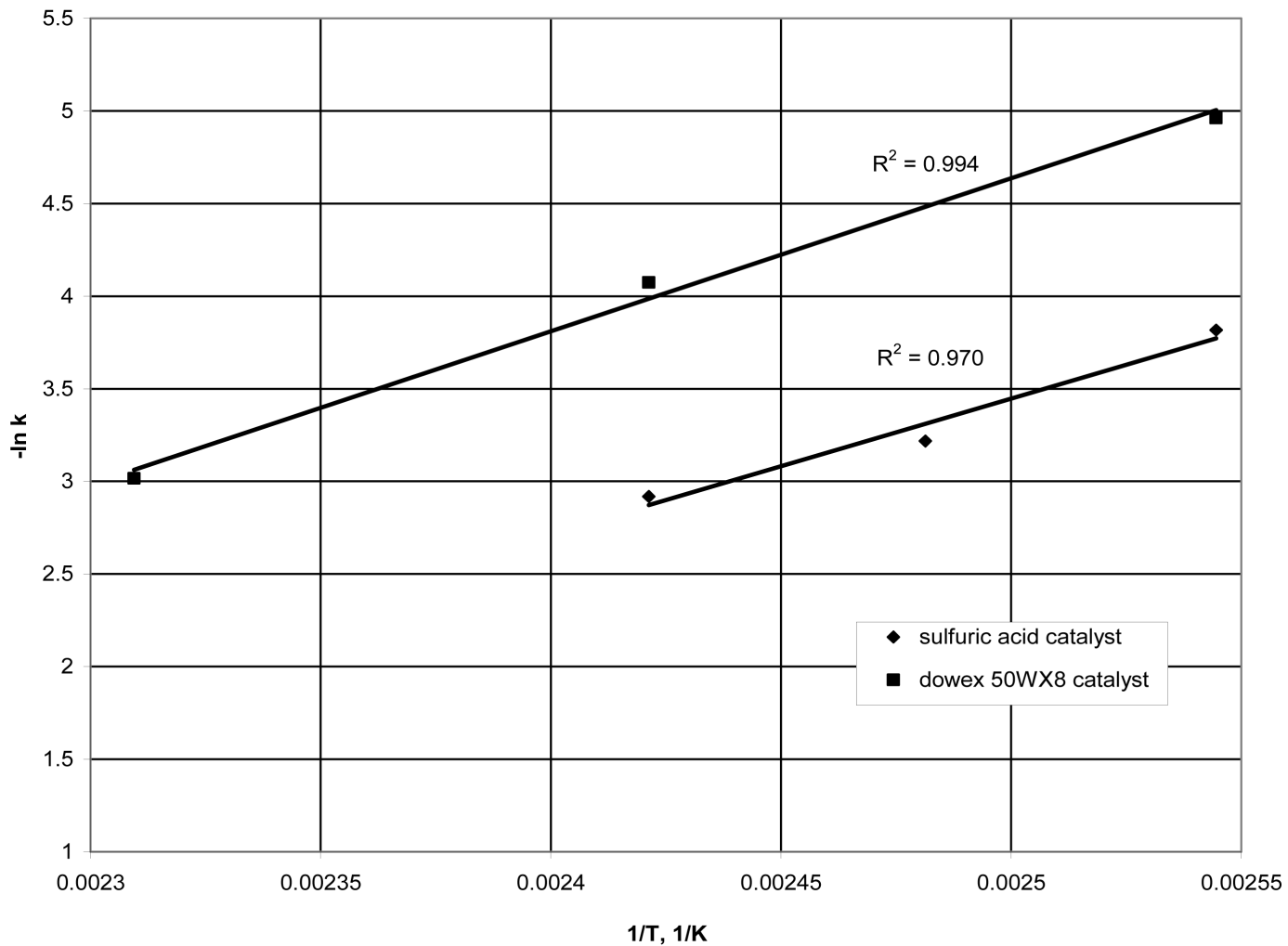

Figure 7. Arrhenius plot for esterification of octanoic acid with n-octanol over sulfuric acid catalyst and over dowex 50WX8 catalyst. 


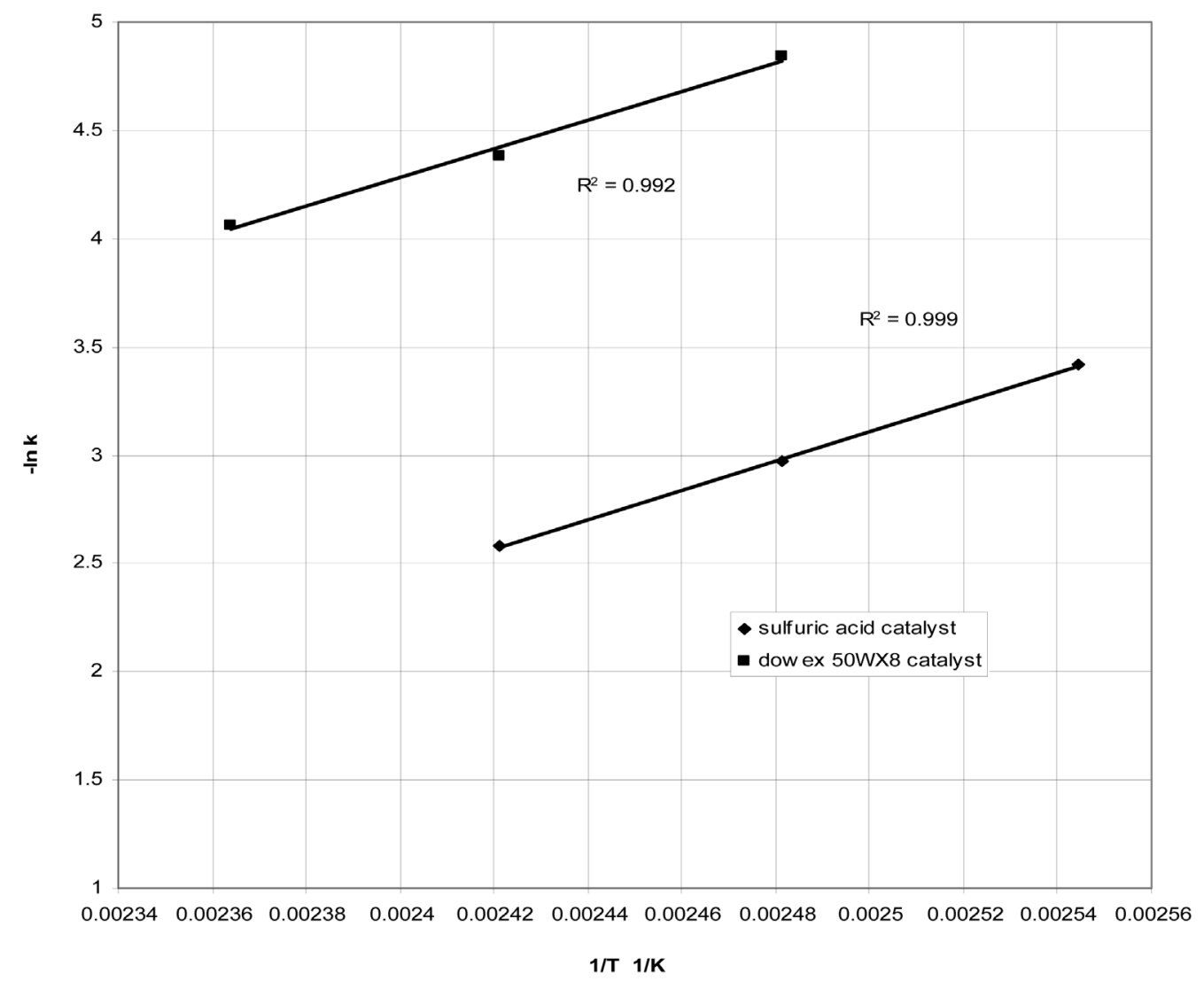

Figure 8. Arrhenius plot for esterification of decanoic acid with n-octanol over sulfuric acid catalyst and over dowex 50WX8 catalyst.

Table 3. Kinetic parameters of reactions.

\begin{tabular}{|c|c|c|c|c|}
\hline $\begin{array}{c}\text { Acid/catalyst } \\
\text { concentration, mass \% }\end{array}$ & Temperature, $\mathrm{K}$ & $\begin{array}{c}\text { Reaction time, } \\
\mathrm{b}=5, \eta=0.95 \mathrm{~min}\end{array}$ & $\begin{array}{c}\mathrm{k}_{0} \cdot \mathrm{E}-04 \\
1 / \mathrm{min}\end{array}$ & $\begin{array}{c}\mathrm{E}, \\
\mathrm{kJ} / \mathrm{mol}\end{array}$ \\
\hline \multirow{3}{*}{$\begin{array}{c}\text { Hexanoic/ } \\
0.025 \text { sulfuric acid }\end{array}$} & 393 & 105 & \multirow{3}{*}{94.034} & \multirow{3}{*}{56.79} \\
\hline & 413 & 45 & & \\
\hline & 423 & 35 & & \\
\hline \multirow{3}{*}{$\begin{array}{c}\text { Hexanoic/ } \\
0.70 \text { dowex W50X8 }\end{array}$} & 403 & 285 & \multirow{3}{*}{4.4891} & \multirow{3}{*}{51.35} \\
\hline & 413 & 195 & & \\
\hline & 423 & 130 & & \\
\hline \multirow{3}{*}{$\begin{array}{c}\text { Octanoic/ } \\
0.025 \text { sulfuric acid }\end{array}$} & 393 & 140 & \multirow{3}{*}{272.51} & \multirow{3}{*}{60.74} \\
\hline & 403 & 80 & & \\
\hline & 413 & 60 & & \\
\hline \multirow{4}{*}{$\begin{array}{c}\text { Octanoic/ } \\
1.25 \text { dowex W50X8 }\end{array}$} & 393 & 460 & \multirow{4}{*}{560.02} & \multirow{4}{*}{68.67} \\
\hline & 403 & 260 & & \\
\hline & 413 & 180 & & \\
\hline & 423 & 120 & & \\
\hline \multirow{3}{*}{$\begin{array}{c}\text { Decanoic/ } \\
0.025 \text { sulfuric acid }\end{array}$} & 393 & 105 & \multirow{3}{*}{117.88} & \multirow{3}{*}{56.84} \\
\hline & 403 & 65 & & \\
\hline & 413 & 45 & & \\
\hline \multirow{3}{*}{$\begin{array}{c}\text { Decanoic/ } \\
1.0 \text { dowex W50X8 }\end{array}$} & 403 & 345 & \multirow{3}{*}{11.527} & \multirow{3}{*}{55.2} \\
\hline & 413 & 235 & & \\
\hline & 423 & 160 & & \\
\hline
\end{tabular}




\section{Conclusions}

Esters of medium-chain fatty acids are now of great interest from both theoretical and practical points of view, so kinetic data on their synthesis is helpful. The nearly complete removal of water formed in the course of reaction and molar excess of alcohol-5:1 or 10:1-allows good conversion degrees of the acids. The data could be approximated for mixtures of medium-chain fatty acids C8 - C10 because of similarity of values of conversion.

Further investigations in the presence of more friendly heterogeneous catalysts-enzymes-will be conducted.

\section{Conflict of Interest}

The authors declare that there was no conflict of interest.

\section{References}

[1] Beare-Rogers, J., Dieffenbacher, A. and Holm, J.V. (2001) Lexicon of Lipid Nutrition (IUPAC Technical Report). Pure and Applied Chemistry, 73, 744-685.

[2] Šalić, A, Pindrić, K. and Zelić, B. (2013) Bioproduction of Food Additives Hexanal and Hexanoic Acid in a Microreactor. Applied Biochemistry and Biotechnology, 171, 2273-2284. https://doi.org/10.1007/s12010-013-0495-5

[3] Fu, L., Bai, Y., Lü, G. and Jiang, D. (2015) Reaction Kinetics of Isopropyl Palmitate Synthesis. Chinese Journal of Chemical Engineering, 23, 1335-1339.

https://doi.org/10.1016/j.cjche.2015.05.004

[4] Srilatha, K., Lingaiah, N., Sai Prasad, P.S., Prabhavathi Devi, B.L.A. and Prasad, R.B.N. (2011) Kinetics of the Esterification of Palmitic Acid with Methanol Catalyzed by 12-Tungstophosphoric Acid Supported on $\mathrm{ZrO}_{2}$. Reaction Kinetics, Mechanisms and Catalysis, 104, 211-226. https://doi.org/10.1007/s11144-011-0334-Z

[5] Ali, S.H., Tarakmah, A., Merchant, S.Q. and Al-Sahhaf, T. (2007) Synthesis of Esters: Development of the Rate Expression for the Dowex 50 Wx8-400 Catalyzed Esterification of Propionic Acid with 1-Propanol. Chemical Engineering Science, 62, 3197-3217. https://doi.org/10.1016/j.ces.2007.03.017

[6] Santos, A.M.B., Martinez, M. and Mira, A.J. (1996) Comparison Study of Lewis Acid Type Catalysts on the Esterification of Octanoic Acid and n-Octyl Alcohol. Chemical Engineering \& Technology, 19, 538-542. https://doi.org/10.1002/ceat.270190611

[7] Urteaga, L., Sanchez, N., Martinez, M. and Aracil, J. (1994) Kinetic Study of the Synthesis of $n$-Octyl Octanoate Using Cobalt Chloride as Catalyst. Chemical Engineering \& Technology, 17, 210-215. https://doi.org/10.1002/ceat.270170310

[8] Mekala, M. and Goli, V.R. (2015) Kinetics of Esterification of Methanol and Acetic Acid with Mineral Homogeneous Acid Catalyst. Chinese Journal of Chemical Engineering, 23, 100-105. https://doi.org/10.1016/j.cjche.2013.08.002

[9] Ali, S.H. and Merchant, S.Q. (2009) Kinetic Study of Dowex 50 Wx8-Catalyzed Esterification and Hydrolysis of Benzyl Acetate. Industrial \& Engineering Chemistry Research, 48, 2519-2532. https://doi.org/10.1021/ie8006787

[10] Ju, I.B., Lim, H.-W., Jeon, W., Suh, D.J., Park, M.-J. and Suh, Y.-W. (2011) Kinetic Study of Catalytic Esterification of Butyric Acid and n-Butanol over Dowex 
50Wx8-400. Chemical Engineering Journal, 168, 293-302.

https://doi.org/10.1016/j.cej.2010.12.086

[11] Kulawska, M., Organek, M. and Organek, W. (2015) Badania kinetyczne syntezy kaprylanów $n$ - i izo-oktylowych w obecności katalizatorów dowex (Kinetic Investigations on the Synthesis of $n$ - and Iso-Octyl Caprylates over Dowex Catalysts). Przemysl Chemiczny, 94, 1381-1384. (in Polish)

[12] Forsythe, C.J. (2013) Influence of Inert Gas Sparging on Fatty Acid Lactylate Esterification Kinetics. Reaction Kinetics, Mechanisms and Catalysis, 108, 263-284. https://doi.org/10.1007/s11144-012-0521-6

[13] McMurry, J.E. (2011) Organic Chemistry. 8th Edition, Brooks Cole, Pacific Grove CA. 